\title{
Simulating regional scale secondary organic aerosol formation during the TORCH 2003 campaign in the southern UK
}

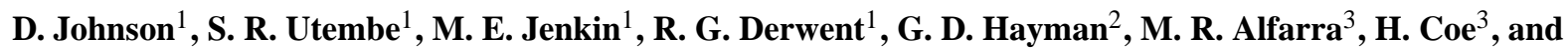 \\ G. McFiggans ${ }^{3}$ \\ ${ }^{1}$ Centre for Environmental Policy, Imperial College London, Silwood Park, Ascot, Berkshire, SL5 7PY, UK \\ ${ }^{2}$ AEA Technology, 551 Harwell, Didcot, Oxfordshire, OX11 0QJ, UK \\ ${ }^{3}$ School of Earth, Environmental and Atmospheric Sciences, Univ. of Manchester, PO Box 88, Manchester M60 1QD, UK
}

Received: 18 July 2005 - Published in Atmos. Chem. Phys. Discuss.: 30 August 2005

Revised: 5 December 2005 - Accepted: 23 December 2005 - Published: 8 February 2006

\begin{abstract}
A photochemical trajectory model has been used to simulate the chemical evolution of air masses arriving at the TORCH field campaign site in the southern UK during late July and August 2003, a period which included a widespread and prolonged photochemical pollution episode. The model incorporates speciated emissions of 124 nonmethane anthropogenic VOC and three representative biogenic VOC, coupled with a comprehensive description of the chemistry of their degradation. A representation of the gas/aerosol absorptive partitioning of ca. 2000 oxygenated organic species generated in the Master Chemical Mechanism (MCM v3.1) has been implemented, allowing simulation of the contribution to organic aerosol (OA) made by semi- and non-volatile products of VOC oxidation; emissions of primary organic aerosol (POA) and elemental carbon (EC) are also represented. Simulations of total OA mass concentrations in nine case study events (optimised by comparison with observed hourly-mean mass loadings derived from aerosol mass spectrometry measurements) imply that the OA can be ascribed to three general sources: (i) POA emissions; (ii) a "ubiquitous" background concentration of $0.7 \mu \mathrm{g} \mathrm{m}^{-3}$; and (iii) gas-to-aerosol transfer of lower volatility products of VOC oxidation generated by the regional scale processing of emitted VOC, but with all partitioning coefficients increased by a species-independent factor of 500 . The requirement to scale the partitioning coefficients, and the implied background concentration, are both indicative of the occurrence of chemical processes within the aerosol which allow the oxidised organic species to react by association and/or accretion reactions which generate even lower volatility products, leading to a persistent, non-volatile secondary organic aerosol (SOA). The contribution of secondary organic mate-
\end{abstract}

Correspondence to: $\mathrm{M}$. E. Jenkin

(m.jenkin@imperial.ac.uk) rial to the simulated OA results in significant elevations in the simulated ratio of organic carbon (OC) to EC, compared with the ratio of 1.1 assigned to the emitted components. For the selected case study events, $[\mathrm{OC}] /[\mathrm{EC}]$ is calculated to lie in the range 2.7-9.8, values which are comparable with the high end of the range reported in the literature.

\section{Introduction}

It is well established that organic material is a significant and variable component of the tropospheric aerosol, accounting for between $10 \%$ and $90 \%$ of the mass of fine particles (e.g., Kanakidou et al., 2005, and references therein). The organic component is normally subdivided into 'primary organic aerosol (POA)', defined as organic compounds which are emitted directly into the atmosphere in particulate form (e.g. from combustion sources), and 'secondary organic aerosol (SOA)', defined as semi- or non-volatile products of the gas-phase oxidation of emitted volatile organic compounds (VOC) which have transferred from the gaseous to the aerosol-phase.

The precursor volatile organic compounds (VOC) can be emitted from both biogenic and anthropogenic sources (e.g. Guenther et al., 1995; Olivier et al., 1996), and it is well documented that their atmospheric degradation plays a central role in the generation of not only SOA, but also other secondary pollutants, most notably ozone (e.g., Leighton, 1961; Finlayson-Pitts and Pitts, 1999; Atkinson, 2000; Jenkin and Clemitshaw, 2000). Fine particles and ozone have harmful impacts on human health and on the environment, and influence the Earth's radiation budget: consequently, a sound understanding of the chemistry and impacts of VOC degradation, and its adequate representation in atmospheric models,

(C) 2006 Author(s). This work is licensed under a Creative Commons License. 
is of central importance to the development of environmental policy on local, regional and global-scale issues.

Emissions speciation data indicate that many hundreds of VOC are emitted (e.g. Goodwin et al., 2001), which possess a variety of physico-chemical properties. Consequently, the mechanism by which each emitted VOC is degraded is essentially unique, and the atmospheric oxidation of all emitted VOC (ultimately to $\mathrm{CO}_{2}$ and $\mathrm{H}_{2} \mathrm{O}$ ) generates thousands of partially oxidised intermediate organic products. By virtue of variations in structure and functional group content, these products possess a wide variety of properties (e.g., reactivity; volatility; photolability), and the distribution of products formed is a major factor in determining the influence that a given precursor VOC has on the formation of SOA, ozone and other secondary pollutants. Modelling studies using detailed emitted VOC speciations and comprehensive descriptions of VOC degradation chemistry thus provide a means of quantifying the roles played by VOC (both individually and collectively) in atmospheric chemistry. They allow the prediction of the concentration distribution of simple and multifunctional oxidised products, thereby allowing a much more detailed appraisal of the contributions made by individual VOC, or VOC classes, to SOA and ozone formation.

In the present paper, and the companion paper (Johnson et al., 2006), a detailed examination of the role of VOC oxidation in the generation of SOA on a regional scale over north-west Europe is described. Building upon the recent study of Utembe et al. (2005), a photochemical trajectory model has been used to simulate the chemical evolution of air masses arriving at a field campaign site in the southern UK during late July and August 2003, a period which included a widespread and prolonged photochemical pollution episode. The model incorporates speciated emissions of 124 non-methane anthropogenic VOC and three representative biogenic VOC (isoprene, $\alpha$-pinene and $\beta$-pinene), coupled with a comprehensive description of the chemistry of their degradation (provided by either the Master Chemical Mechanism, MCM, or the Common Representative Intermediates, CRI, Mechanism). Based on the method of Pankow (1994), a representation of the gas/aerosol absorptive partitioning of ca. 2000 oxygenated organic species generated in MCM v3.1 has been developed and implemented, allowing simulation of the contribution to organic aerosol (OA) made by semiand non-volatile products of VOC oxidation; emissions of POA and elemental carbon (EC) are also represented. In the present paper, simulations of the mass concentrations of the various carbonaceous aerosol components and ozone at the arrival location are presented, and compared with observations made during the first campaign of the Tropospheric Organic Chemistry Experiment (TORCH). Simulations of total OA mass concentrations in nine case study events are compared with mass loadings derived from aerosol mass spectrometry (AMS) measurements. These are used to refine and optimise the representation of SOA formation, and conclusions are drawn concerning the role of accretion chemistry in the condensed organic phase, and the contribution to total OA made by the products of VOC oxidation on a regional scale for the series of case studies. In the companion paper, the detailed chemical composition of the simulated SOA is presented, and the contribution made by the oxidation of specific emitted anthropogenic and biogenic VOC for the series of case studies is examined.

\section{The TORCH 2003 campaign}

The first field campaign of the Tropospheric Organic Chemistry Experiment (TORCH) consortium project took place in late July and August 2003 at Writtle College, Writtle, Essex, UK $\left(51.74^{\circ} \mathrm{N} ; 0.42^{\circ} \mathrm{E}\right)$, approximately $40 \mathrm{~km}$ to the northeast of central London. The site was a ca. 1.5 ha grass field situated to the south east of the main college buildings, and was un-impacted by any significant local vehicular, domestic or industrial sources. It was situated ca. $3 \mathrm{~km}$ from the nearest major " $\mathrm{A}$ " road (to the south), with the prevailing south-westerly fetch passing over an area of flat arable farmland with scattered buildings for a distance of approximately $15 \mathrm{~km}$ before reaching the eastern edge of the major M25 motorway. All instrumentation at the site was housed in mobile laboratories, with a common $14 \mathrm{~m}$ sampling tower and low residence time manifold. Measurements of ambient concentrations of a variety of species and meteorological parameters were made by six UK research institutes. Of particular importance to the present study were measurements of organic aerosol loading and composition (see McFiggans et al., 2005), and measurements of gas-phase light hydrocarbons, small oxygenated organic species and ozone, made by the University of York (Utembe et al., 2005). The nominal duration of the campaign was from 27 July-30 August.

A variety of meteorological conditions were observed during the five-week campaign, which can be broadly subdivided into five periods: (i) The early part of the campaign, up to 2 August, was dominated by prevailing winds from the Atlantic, with air mainly arriving at the measurement site from a westerly or south-westerly direction. During this time, the site was often situated in the London plume. (ii) The most significant feature of the campaign was a persistent period of high pressure, observed over much of north-west Europe, which brought stable conditions from about 3-12 August. This was accompanied by successive days of long hours of sunshine, with high temperatures in excess of $30^{\circ} \mathrm{C}$ on several days. The period was characterised by low wind speeds (2-4 $\mathrm{m} \mathrm{s}^{-1}$ ), with broad air flow from the European continent and recirculation over the UK, such that the near-stagnant, highly-processed air arrived at the site from a variety of directions. The site was generally not in the London plume during this period. (iii) From 13-17 August, the air arrived from the northern sector, typically originating in the North Atlantic and passing over the northern UK or the North Sea prior to arrival. (iv) The period from 18-22 August was dominated 
by westerly winds, with a brief period during which the site was in the London plume. (v) The final part of the campaign, from 23 August, was once again characterised by air arriving from the northern sector, originating in the North Atlantic or the Arctic.

\section{The Photochemical Trajectory Model}

\subsection{Model overview}

The Photochemical Trajectory Model (PTM) used in the present study is based on that which has been widely applied to the simulation of photochemical ozone formation in north-west Europe (Derwent et al., 1996, 1998; Jenkin et al., 2002a), and used recently to simulate distributions of gasphase organics during the TORCH 2003 campaign (Utembe et al., 2005). The PTM simulates the chemical development in a well-mixed boundary layer air parcel being advected along multi-day trajectories. The air parcel picks up emissions of $\mathrm{NO}_{\mathrm{x}}, \mathrm{CO}, \mathrm{SO}_{2}$, methane, anthropogenic VOC and biogenic VOC, which are processed using an appropriate description of the chemical and photochemical transformations leading to the formation of ozone and other secondary pollutants. The model was specifically formulated to represent the broad meteorological conditions associated with photochemical pollution episodes in the UK, and the diurnal variation in atmospheric boundary layer depth and relative humidity are therefore represented as a climatological mean over a number of photochemical episodes (Derwent et al., 1996). The maximum boundary layer depth is $1300 \mathrm{~m}$. To allow the diurnal variation to be represented, the model is divided into two vertical layers at nightfall, through the establishment of a shallow inversion layer (300 $\mathrm{m}$ deep), which persists throughout the night. At sunrise, this lower layer expands and gradually entrains the air trapped aloft overnight, until the full boundary layer height is achieved at $1400 \mathrm{hr}$. As described in detail previously (Derwent et al., 1996), removal of species from the lower layer also occurs by dry deposition to the ground or sea surface.

\subsection{Emissions}

As in the study of Utembe et al. (2005), the spatial disaggregation of UK emissions of methane, anthropogenic VOC, $\mathrm{NO}_{\mathrm{x}}, \mathrm{CO}$ and $\mathrm{SO}_{2}$ was based on the 1998 maps defined by the National Atmospheric Emissions Inventory (NAEI) (http://www.aeat.co.uk/netcen/airqual). For other European countries, the mapped emissions were taken from the original study of Derwent et al. (1996), based on EC CORINAIR and EMEP. The emissions were scaled so that the country totals were appropriate to 2003 , based on interpolation of historical and projected figures available from EMEP (http://www.emep.int) and the NAEI, and reported in AQEG (2004, 2005). The speciation of the emitted anthropogenic VOC was also based on the NAEI, which identifies ca. 650 individual species (Goodwin et al., 2001). To allow coupling with the chemical mechanisms (see below), the speciation was represented by 124 species which collectively account for ca. $70 \%$ of the NAEI emissions, by mass. As described by Utembe et al. (2005), the outstanding $>500$ species, which each makes a small contribution to the remaining 30\%, were emitted in the form of appropriate surrogates, which were assigned on the basis of chemical class and reactivity. Temporal variations were applied to the emissions of anthropogenic VOC and $\mathrm{NO}_{\mathrm{x}}$ to describe the seasonal, day-of-week and hour-of-day dependence of the emissions, as described in detail elsewhere (Jenkin et al., 2000; Utembe et al., 2005).

The representation of biogenic VOC emissions for the EMEP domain was based on the methodology described by Dore et al. (2003a). Emissions of isoprene, monoterpenes and "other biogenic VOC" were thus described in terms of mapped emissions potentials (based on high-resolution land use data and emissions factors for a large number of plant species), and environmental correction factors incorporating the influence of variations in surface temperature and photosynthetically active radiation (PAR) along the applied trajectory paths. This allowed a more rigorous representation of the magnitudes and temporal variations of the biogenic VOC emission rates relevant to the TORCH 2003 campaign period, compared with the previous study of Utembe et al. (2005), in which emission rates were based on averaged monthly and diurnal profiles. The updated representation therefore resulted in a greater simulated input of biogenic VOC during the high temperature, anticyclonic period of the campaign (period (ii)), than in the previous work. To allow coupling with the chemical mechanisms, monoterpenes and "other biogenic VOC" were emitted as $67 \% \alpha$-pinene and $33 \% \beta$-pinene. Although it is recognised that many individual VOC are actually emitted (e.g. Owen et al., 2001), and that the speciation varies with vegetation type and other factors (e.g. season: Llusia and Peñuelas, 2000), the applied speciation is broadly consistent with the reported dominance of cyclic terpene emissions and the relative emissions of monoterpenes with endocyclic double bonds (for which $\alpha$-pinene is a reasonable representative) and with exocyclic double bonds (for which $\beta$-pinene is a reasonable representative), as reported in a number of studies of a variety of vegetation types (e.g. He et al., 2000; Llusia and Peñuelas, 2000; Boissard et al., 2001; Janson et al., 2001; Owen et. 2001; Spänke et al., 2001; Kanakidou et al., 2005 and references therein).

Emitted primary organic aerosol (POA) contributes to the ambient organic aerosol loading, and is also important in providing a partitioning medium for the gas-to-aerosol transfer of oxidised organic material generated from the oxidation of emitted VOC. In the PTM, emissions of POA were quantified relative to mass emissions of $\mathrm{NO}_{\mathrm{x}}$, on the basis of welldefined correlations of $\mathrm{NO}_{\mathrm{x}}$ and fine organic particulate mass $(\leq 200 \mathrm{~nm})$ observed at urban locations, using AMS (Allan et 
al., 2003; Alfarra, 2004):

$E_{\mathrm{POA}}=0.012 E_{\mathrm{NO}_{\mathrm{x}}}$

Consistent with the convention adopted in emissions inventories for the purposes of reporting mass emissions of $\mathrm{NO}_{\mathrm{x}}$, the proportionality constant defined here notionally assumes that $\mathrm{NO}_{\mathrm{x}}$ is emitted entirely in the form of $\mathrm{NO}_{2}$. Emissions of elemental (or black) carbon were also represented in the model, on the basis of the lower limit ratio of organic carbon (OC) to elemental carbon (EC) of 1.1 observed in Birmingham by Castro et al. (1999), and with the assumption that the emitted POA mass exceeds the emitted OC mass by a factor of 1.2 (i.e. $20 \%$ of emitted POA mass is due to elements other than carbon, a reasonable assumption for organic material mainly composed of higher molecular weight hydrocarbons and $\mathrm{PAH})$ :

$E_{\mathrm{EC}}=E_{\mathrm{POA}} /(1.1 \times 1.2)$

Although combustion processes dominate carbonaceous aerosol emissions sources in the region of this study, it is recognised that relating their emissions to those of $\mathrm{NO}_{\mathrm{x}}$ is an approximation, given that the observed correlations relate primarily to road transport and may not necessarily apply to other combustion sources. Nevertheless, comparison of the UK inventory emission totals for $\mathrm{NO}_{\mathrm{x}}$ and fine particulate mass fractions ( $\mathrm{PM}_{1}$ and $\left.\mathrm{PM}_{0.1}\right)$, for the variety of combustion source sectors (Table 1), indicates that the present procedure (based on ambient observations) provides a consistent representation for road transport and the combustion sources total, even if some of the minor source categories are less well described. Thus, the summed mass emissions of POA and $\mathrm{EC}$, estimated relative to $\mathrm{NO}_{\mathrm{x}}$ by the present method (based on $\leq 200 \mathrm{~nm}$ particles), give totals which are intermediate to the inventory estimates for $\mathrm{PM}_{0.1}$ and $\mathrm{PM}_{1}$, and much closer to those for $\mathrm{PM}_{0.1}$. The carbonaceous aerosols were removed from the lower layer of the model by dry deposition, with a deposition velocity of $0.1 \mathrm{~cm} \mathrm{~s}^{-1}$, corresponding to a lifetime of ca. 2 weeks.

\subsection{Gas-phase chemistry}

The chemical processing was represented by either the Master Chemical Mechanism, version 3.1 (MCM v3.1) or by the Common Representative Intermediates (CRI) mechanism. MCM v3.1 is a near-explicit mechanism, which describes the complete degradation of methane and 124 emitted nonmethane VOC and the associated formation of ozone and other secondary pollutants, as described in detail elsewhere (Jenkin et al., 1997, 2003; Saunders et al., 2003; Bloss et al., 2005). The mechanism contains ca. 14,000 reactions, which represent the chemistry of ca. 5000 molecular and free radical species. It therefore represents the formation of intermediate oxygenated compounds containing carbonyl, nitrate, peroxy nitrate, hydroxyl, hydroperoxy, acid and peracid groups, and multifunctional species containing two or more of these substitutent groups. In the present study, the MCM v3.1 version of the model (denoted PTM-MCM) has been used to simulate the development of the detailed chemical composition of air masses along selected case study trajectories.

The CRI mechanism treats the degradation of the full suite of emitted VOC using about 570 reactions of 250 species, as described by Jenkin et al. (2002b). It therefore provides an economical alternative to the near-explicit representation in the MCM, thereby allowing a much larger number of trajectory calculations to be carried out comparatively efficiently. As the name suggests, the CRI mechanism contains a series of generic intermediate radicals and products, which mediate the breakdown of larger emitted VOC into smaller fragments (e.g., formaldehyde), the chemistry of which is treated explicitly. The mechanism was optimised in terms of its ability to generate ozone, by comparison with the MCM, using the PTM operating on a standard five-day trajectory (Jenkin et al., 2002b). In the present study, the CRI mechanism version of the model (denoted PTM-CRI) has been used for simulations of the chemical processing along 156 trajectories throughout the TORCH 2003 campaign.

\subsection{Trajectories and initialisation}

The model was used to simulate the chemical development over a $96 \mathrm{~h}$ period along trajectories arriving at the Writtle site. The trajectories were obtained from the NOAA on-line trajectory service (http://www.arl.noaa.gov/ ready/hysplit4.html) for arrival times of 00:00, 06:00, 12:00 and 18:00 $\mathrm{h}$ for the period 26 July-2 September 2003, and for an arrival altitude of $300 \mathrm{~m}$, using the "model vertical velocity" option. The associated temperatures were used to represent air mass temperature in the PTM simulations. Surface temperatures required for the calculation of biogenic emissions were obtained by correcting for altitude, assuming a global mean tropospheric lapse rate of $-6.5^{\circ} \mathrm{C} \mathrm{km}^{-1}$ (e.g., Hartmann, 1994).

The initial concentrations for the majority of species in the chemical mechanisms were set to zero. As described by Utembe et al. (2005), the initial concentrations for a limited number of inorganic, carbonyl and light hydrocarbon species were set to realistic tropospheric background concentrations for a relatively clean boundary layer: ozone (34 ppb); $\mathrm{NO}(20 \mathrm{ppt}) ; \mathrm{NO}_{2}$ (100 ppt); $\mathrm{SO}_{2}(100 \mathrm{ppt}) ; \mathrm{H}_{2}$ (550 ppb); $\mathrm{CO}(120 \mathrm{ppb})$; methane (1.7 ppm); ethane (1.2 ppb); propane (180 ppt); butane (70 ppt); methylpropane (86 ppt); pentane (24 ppt); 2-methylbutane (27 ppt); hexane (11 ppt); heptane (28 ppt); octane (2ppt); ethene (96 ppt); propene (32 ppt); but-1-ene (10 ppt); methylpropene ( $0.4 \mathrm{ppt})$; trans-but-2-ene (11 ppt); cis-but-2-ene (2 ppt); pent-1-ene (10 ppt); benzene (46 ppt); toluene (42 ppt); o-xylene (23 ppt); m-xylene $(8 \mathrm{ppt})$; p-xylene (8pt); formaldehyde (300 ppt); acetaldehyde $(150 \mathrm{ppt})$; acetone $(600 \mathrm{ppt})$. The initial concentrations 
Table 1. Comparison of UK total mass emissions for POA and EC using the method applied in the present study with NAEI totals for particulate mass fractions (see text).

\begin{tabular}{|c|c|c|c|c|c|c|c|c|}
\hline Combustion source & $\mathrm{NO}_{\mathrm{x}}$ & $\mathrm{PM}_{10}$ & $\mathrm{PM}_{2.5}$ & $\mathrm{PM}_{1}$ & $\mathrm{PM}_{0.1}$ & POA & $\mathrm{EC}$ & $\mathrm{POA}+\mathrm{EC}$ \\
\hline & \multicolumn{5}{|c|}{ UK NAEI, 2001 (ktonne) $^{\mathrm{a}}$} & \multicolumn{3}{|c|}{ Current method (ktonne) ${ }^{b}$} \\
\hline Road transport & 781 & 30 & 29 & 26 & 15 & 9.4 & 7.1 & 16.5 \\
\hline Energy production & 460 & 20 & 10 & 6 & 3 & 5.5 & 4.2 & 9.7 \\
\hline Industry & 171 & 23 & 16 & 10 & 5 & 2.1 & 1.6 & 3.6 \\
\hline Commercial/residential & 107 & 38 & 20 & 14 & 3 & 1.3 & 1.0 & 2.3 \\
\hline Other transport & 153 & 9 & 7 & 7 & 1 & 1.8 & 1.4 & 3.2 \\
\hline Total & 1672 & 120 & 82 & 63 & 27 & 20.1 & 15.2 & 35.3 \\
\hline
\end{tabular}

Notes

a Taken from Dore et al. (2003b). Data for 2001 are considered, being the most recent historical (i.e. not projected) information available at this level of detail at the time of the present study. Finer PM fractions determined from PM $_{10}$ totals for 236 sectors and subsectors, and particle size distributions assigned to each of the sectors and subsectors, based on USEPA (1995) and TNO (1997).

${ }^{\mathrm{b}}$ Calculated from tabulated $\mathrm{NO}_{\mathrm{x}}$ emission total and correlations for $\mathrm{E}_{\mathrm{POA}}$ and $\mathrm{E}_{\mathrm{EC}}$ (based on observations of organic particulate $\leq 200 \mathrm{~nm}$ ) described in the text. Apparent summation error for "industry" results from rounding individual entries to one decimal place.

of the hydrocarbons were based on the summertime measurements of Penkett et al. (1993) over the North Atlantic.

\section{Representation of secondary organic aerosol}

The gas-phase oxidation of emitted VOC leads to the formation of semi- and non-volatile products which may transfer from the gas-phase to a condensed particle-phase, thus contributing to the mass of organic aerosol. Particulate material formed in this way is termed secondary organic aerosol (SOA). Following the methodology employed and described previously by Jenkin (2004) ${ }^{1}$ and Johnson et al. (2004a, $2005)^{1}$, gas-to-particle transfer reactions were defined for around 2000 reaction products - these compounds having been chosen, from the total of near 3000 closed-shell species in the MCM v3.1, according to the criterion that their estimated normal boiling temperatures are greater than $450 \mathrm{~K}$ - following the absorptive partitioning theory of Pankow (1994). In this theory, the phase-partitioning of a given species is defined by the thermodynamic equilibrium of that species between the gas-phase and absorbed in a condensed organic-phase, with an associated partitioning (equilibrium) coefficient, $K_{p}$, which is given by:

$K_{p}=\frac{7.501 \times 10^{-9} R T}{M W_{o m} \zeta p_{L}^{\circ}}$

Here, $R$ is the ideal gas constant $\left(8.314 \mathrm{~J} \mathrm{~K}^{-1} \mathrm{~mol}^{-1}\right), T$ is the temperature $(\mathrm{K}), M W_{\text {om }}$ is the mean molecular weight of the absorbing particulate organic material $\left(\mathrm{g} \mathrm{mol}^{-1}\right), \zeta$ is the activity coefficient of the species in the condensed

\footnotetext{
${ }^{1}$ These studies simulated observed aerosol formation in smog chamber experiments.
}

organic-phase and $p_{L}{ }^{\circ}$ is its (probably sub-cooled) liquid vapour pressure (Torr). The units of $K_{p}$ are $\mathrm{m}^{3} \mu \mathrm{g}^{-1}$. A value of unity for $\zeta$ was assumed for all partitioning oxidation products as it is expected that aerosol particles comprise mixtures of similar-types of molecules. This assumption has been made previously in a number of studies. (e.g. Odum et al., 1996; Kamens et al., 1999; Jang and Kamens, 2001a; Jenkin, 2004; Johnson et al., 2004a, 2005). The liquid vapour pressure (again, probably sub-cooled with respect to the pure compound) of a given species was estimated using an expanded semi-empirical form of the Clausius-Clapeyron equation (see Baum, 1998):

$\ln \left(\frac{p_{L}^{\circ}}{760}\right)=\frac{-\Delta S_{\text {vap }}\left(T_{b}\right)}{R}\left[1.8\left(\frac{T_{b}}{T}-1\right)-0.8\left(\ln \frac{T_{b}}{T}\right)\right]$

where $T_{b}$ is the normal boiling temperature and $\Delta S_{\text {vap }}$ is the entropy change of vaporisation at that temperature, for the species of interest. $T_{b}$ values were estimated using the fragmentation method of Joback and Reid (1987), modified by Stein and Brown (1994), as implemented by ChemDraw Ultra version 7.0.1 (Cambridgesoft, 2002), a chemical drawing software package. As described by Johnson et al. (2004a, 2005), the effect/contribution of nitrate substituents $\left(\mathrm{ONO}_{2}\right)$ on boiling temperatures had to be specially accounted for $\Delta S_{\text {vap }}$ values were estimated using the Kitiakowsky equation (or Trouton-Hildebrand-Everett rule) with corrections for polar compounds and compounds with hydrogen-bonding capability, according to Vetere (see Baum, 1998). The partitioning coefficient describes the extent to which a given product is transferred from the gas-phase to the particle-phase, and hence the particle-phase concentration can be evaluated:

$F_{i, o m}=K_{p} \times A_{i,} \times M_{o}$

Here, $F_{i, o m}$ is the concentration of species $i$ in the condensed organic-phase, $A_{i}$ is its gas-phase concentration and 


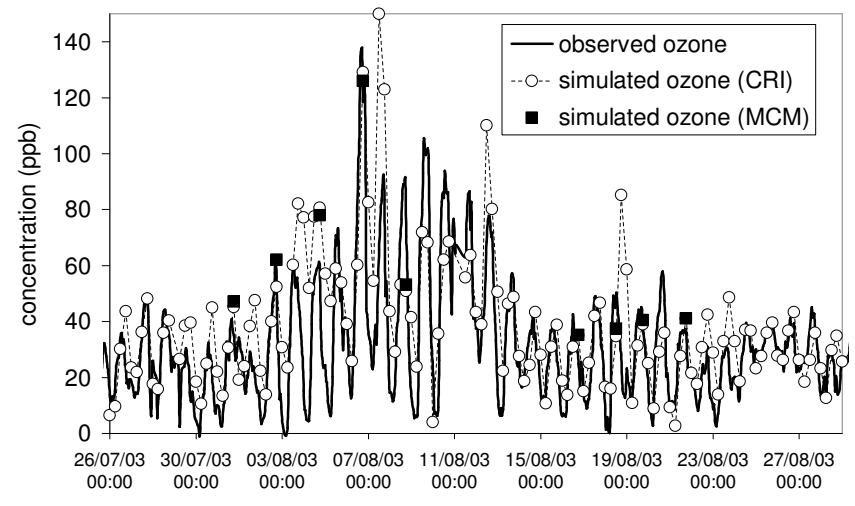

Fig. 1. Comparison of observed hourly mean ozone concentrations with those simulated for the entire campaign with the PTM-CRI, and for nine case study trajectories with PTM-MCM. The broken line joining the PTM-CRI points is to guide the eye, and is not intended to infer intermediate simulated concentrations.

$M_{o}$ is the total mass concentration of condensed organic material $\left(\mu \mathrm{g} \mathrm{m}^{-3}\right)$. Partitioning equilibria were represented dynamically by defining each species-dependent $K_{p}$ value in terms of an absorption $\left(k_{\text {in }}\right)$ and a desorption $\left(k_{\text {out }}\right)$ rate coefficient, with $K_{p}=k_{\text {in }} / k_{\text {out }}$. As in the previous studies of Jenkin (2004) and Johnson et al. (2004a, 2005), a value of $6.2 \times 10^{-3} \mathrm{~m}^{3} \mu \mathrm{g}^{-1} \mathrm{~s}^{-1}$ for $k_{\text {in }}$ was assumed for all partitioning reactions. Variation in $k_{\text {in }}$ by an order of magnitude in either direction had no effect upon the simulated aerosol mass concentrations. Thus species-dependent $K_{p}$ were expressed in the model in terms of species-dependent values for $k_{\text {out }}$. Variations in $K_{p}$ as the secondary organic aerosol mass evolved (i.e. as the average molecular weight of the absorbing condensed organic material changed - see Eq. (3)) were accounted for by evaluating $k_{\text {out }}$ as:

$k_{\text {out }}=k_{\text {out }}^{\circ} \times\left(M W_{\text {om }} / M W_{\text {om }}^{\circ}\right)$

where $M W_{o m}^{\circ}$ is a reference average molecular weight (arbitrarily taken to be 130) which was used to calculate speciesdependent, reference desorption rate coefficients $\left(k_{\text {out }}^{\circ}\right)$ in order to obtain time-evolving $K_{p}$ values. $M W_{o m}$ was calculated at each time-step in the model.

At this point it is worth making a further note about the smog chamber simulations of Jenkin (2004) and Johnson et al. (2004a, 2005) in which, collectively, SOA formation was investigated from the ozonolysis of $\alpha$ - and $\beta$-pinene, and the photooxidation of toluene, benzene, $p$-xylene and 1,3,5trimethylbenzene. In order to match the mass concentrations of SOA observed in the various experiments, it was necessary to scale all phase partitioning coefficients by a factor of between 5 and 100 (depending on the system studied) and this was interpreted in terms of the occurrence of unaccounted for association, or accretion, chemistry taking place inside the growing organic aerosol. The need to scale partitioning coef- ficients in simulating the field data considered in the present investigation is discussed later in Sects. 5.3 and 5.5.

\section{Results and discussion}

\subsection{Simulations of gas-phase species}

The PTM-CRI was used to simulate the chemical development of air parcels arriving at the Writtle site at six-hourly resolution for the entire TORCH 2003 campaign. As with all simulations in the present study, this was carried out using the FACSIMILE for Windows kinetics integration package, version 3.5 (MCPA Software). Figure 1 shows a comparison of the simulated ozone concentrations at the arrival point with those observed. The model is able to recreate the general variations of ozone through out the campaign, with the updated representation of biogenic VOC emissions (described in Sect. 3.2) leading to an increase in simulated ozone concentrations during the highest temperature period (6-11 August), when compared with the previous simulations reported by Utembe et al. (2005), and a generally improved agreement with observations during that period. With some exceptions, the 18:00 $\mathrm{h}$ arrival simulations provide a good description of the variation of the daily maximum hourly-mean ozone concentration throughout the campaign. On three days (most notably 7 August), the model significantly overestimates the maximum ozone concentration, whereas on two days (most notably 8 August), a significant underestimation is apparent.

In preparation for the organic aerosol simulations described below, nine case study events were initially selected for detailed simulation with the PTM-MCM (see Table 2). Selection was based primarily on availability of organic aerosol observations, but also ensured that a variety of air mass histories were being considered. Figure 1 demonstrates that the ozone concentrations simulated with the PTM-MCM for these nine events agree well with those simulated with the PTM-CRI.

Three of the nine case study events (2, 4 and 6 August) were also considered previously by Utembe et al. (2005) for detailed characterisation of the ambient distributions of gasphase carbonyls. Comparison of the carbonyl distributions simulated with the current version of the PTM-MCM with those reported by Utembe et al. (2005), reveal close agreement for the first two events, but some interesting differences for the 6 August event, when the prevailing temperatures were ca. $10-12^{\circ} \mathrm{C}$ higher than average. These differences are a direct result of using trajectory specific temperatures in the current version of the model, and can be explained by a combination of the increased input of biogenic VOC and the direct influence of temperature on some competing reactions in the MCM. Figure 2 presents a correlation of the simulated concentrations in the two studies, which includes data for a number of classes of carbonyl compound which were 
Table 2. Summary of simulated case study events used to optimise the secondary organic aerosol code.

\begin{tabular}{|c|c|c|c|c|c|c|c|c|c|}
\hline $\begin{array}{l}\text { Trajectory Arrival Date } \\
\text { (Time) }\end{array}$ & $\begin{array}{l}31 / 07 / 03 \\
(18: 00)\end{array}$ & $\begin{array}{l}02 / 08 / 03 \\
(18: 00)\end{array}$ & $\begin{array}{l}04 / 08 / 03 \\
(18: 00)\end{array}$ & $\begin{array}{l}06 / 08 / 03 \\
(18: 00)\end{array}$ & $\begin{array}{l}08 / 08 / 03 \\
(18: 00)\end{array}$ & $\begin{array}{l}16 / 08 / 03 \\
(18: 00)\end{array}$ & $\begin{array}{l}18 / 08 / 03 \\
(12: 00)\end{array}$ & $\begin{array}{l}19 / 08 / 03 \\
(18: 00)\end{array}$ & $\begin{array}{l}21 / 08 / 03 \\
(18: 00)\end{array}$ \\
\hline Arrival direction $^{\mathrm{a}}$ & SW & W & SE & W & $\mathrm{N}$ & $\mathrm{E}$ & $\mathrm{W}$ & W & W \\
\hline Air mass origin ${ }^{\mathrm{a}}$ & $\begin{array}{l}\text { Atlantic- } \\
\text { Ireland- } \\
\text { Southern } \\
\text { UK }\end{array}$ & $\begin{array}{l}\text { Atlantic- } \\
\text { Western UK }\end{array}$ & $\begin{array}{l}\text { Atlantic-North } \\
\text { Eastern France- } \\
\text { North Sea }\end{array}$ & $\begin{array}{l}\text { France-Southern } \\
\text { UK }\end{array}$ & $\begin{array}{l}\text { North Sea- } \\
\text { Germany-North } \\
\text { Western UK }\end{array}$ & $\begin{array}{l}\text { Atlantic- } \\
\text { North Sea }\end{array}$ & $\begin{array}{l}\text { North Sea- } \\
\text { Southern UK }\end{array}$ & $\begin{array}{l}\text { Atlantic-Ireland- } \\
\text { Western UK }\end{array}$ & $\begin{array}{l}\text { Atlantic- } \\
\text { Western UK }\end{array}$ \\
\hline Average $\mathrm{E}_{\mathrm{AVOC}} \mathrm{b} / \mu \mathrm{g} \mathrm{m}^{-2} \mathrm{hr}^{-1}$ & 234 & 496 & 349 & 1102 & 189 & 96.0 & 507 & 138 & 195 \\
\hline Average $\mathrm{E}_{\mathrm{BVOC}} \mathrm{b} / \mu \mathrm{g} \mathrm{m}^{-2} \mathrm{hr}^{-1}$ & 9.08 & 21.8 & 23.4 & 102 & 28.4 & 12.2 & 14.7 & 10.9 & 8.26 \\
\hline 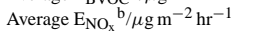 & 243 & 403 & 323 & 941 & 306 & 80.2 & 354 & 214 & 240 \\
\hline $\mathrm{E}_{\mathrm{BVOC}} / \mathrm{E}_{\mathrm{AVOC}}$ & 0.039 & 0.044 & 0.067 & 0.093 & 0.150 & 0.127 & 0.029 & 0.079 & 0.042 \\
\hline $\mathrm{E}_{\mathrm{VOC}} / \mathrm{E}_{\mathrm{NO}}$ & 1.00 & 1.28 & 1.15 & 1.28 & 0.71 & 1.35 & 1.47 & 0.70 & 0.85 \\
\hline Observed $[\mathrm{OA}]_{1 \text { hr mean }} / \mu \mathrm{g} \mathrm{m}^{-3}$ & 1.91 & 3.64 & 4.02 & 6.92 & 5.52 & 0.84 & 2.78 & 1.24 & 0.93 \\
\hline Observed $[\mathrm{OA}]_{5} \mathrm{hrmean}^{c} / \mu \mathrm{g} \mathrm{m}^{-3}$ & $1.81 \pm 0.14$ & $3.68 \pm 0.57$ & $3.83 \pm 0.31$ & $7.17 \pm 0.47$ & $5.72 \pm 0.36$ & $0.97 \pm 0.22$ & $2.92 \pm 0.32$ & $1.55 \pm 0.50$ & $1.31 \pm 0.38$ \\
\hline Total simulated $[\mathrm{OA}] / \mu \mathrm{g} \mathrm{m}^{-3}$ & 1.54 & 2.96 & 2.19 & 6.96 & 2.26 & 0.99 & 2.10 & 1.21 & 1.19 \\
\hline Simulated $[\mathrm{POA}] / \mu \mathrm{g} \mathrm{m}^{-3}$ & 0.33 & 0.63 & 0.41 & 1.25 & 0.45 & 0.07 & 0.61 & 0.22 & 0.26 \\
\hline Simulated $[\mathrm{SOA}]^{\mathrm{d}} / \mu \mathrm{g} \mathrm{m}^{-3}$ & 1.21 & 2.33 & 1.78 & 5.71 & 1.81 & 0.92 & 1.49 & 0.99 & 0.93 \\
\hline Simulated $[\mathrm{EC}] / \mu \mathrm{g} \mathrm{m}^{-3}$ & 0.25 & 0.47 & 0.31 & 0.95 & 0.33 & 0.05 & 0.46 & 0.17 & 0.19 \\
\hline$\sum_{i}[O P] i, T b \geq 450 \mathrm{~K}^{\mathrm{e}} / \mu \mathrm{g} \mathrm{m}^{-3}$ & 4.86 & 11.89 & 5.96 & 30.5 & 7.05 & 3.85 & 9.83 & 3.90 & 3.85 \\
\hline$\sum_{i}^{i}[O P] i, T b<450 \mathrm{~K}^{\mathrm{e}} / \mu \mathrm{g} \mathrm{m}^{-3}$ & 12.7 & 24.0 & 14.7 & 64.9 & 13.0 & 8.08 & 23.7 & 9.61 & 10.8 \\
\hline
\end{tabular}

a based on NOAA trajectories;

$\mathrm{b}$ mean mass emission rates of anthropogenic VOC $\left(\mathrm{E}_{\mathrm{AVOC}}\right)$, biogenic VOC $\left(\mathrm{E}_{\mathrm{BVOC}}\right)$ and $\mathrm{NO}_{\mathrm{x}}\left(\mathrm{E}_{\mathrm{NO}_{\mathrm{x}}}\right.$; as $\left.\mathrm{NO}_{2}\right)$ during $96 \mathrm{~h}$ simulation time;

${ }^{c}$ uncertainty intervals are the standard deviation $( \pm \sigma)$ of five hour periods centred around the quoted times;

$\mathrm{d}$ sum of the simulated total concentration of partitioned VOC oxidation products plus a constant background concentration of organic aerosol of $0.7 \mu \mathrm{g} \mathrm{m}^{-3}$ (see text);

e simulated total gas and aerosol-phase concentration of "volatile" (estimated $T_{b}<450 \mathrm{~K}$ ) and "semi-/non-volatile" (estimated $T_{b} \geq 450 \mathrm{~K}$ ) VOC oxidation products (OP) at the arrival point.

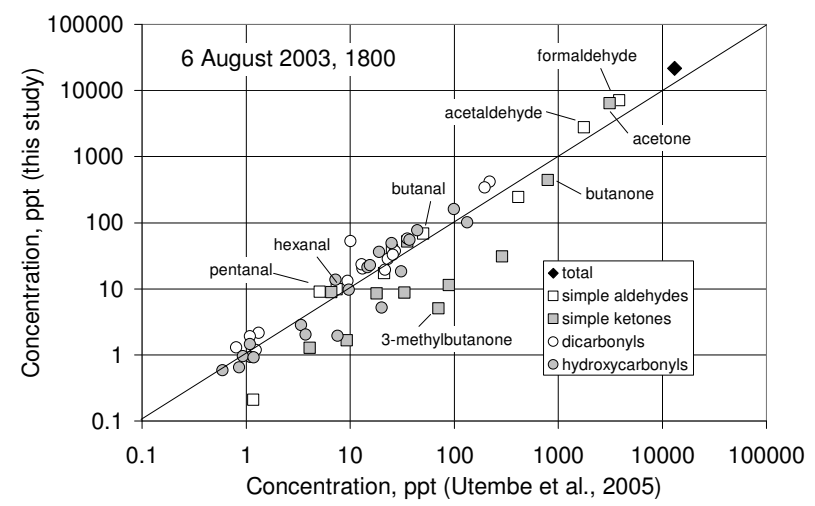

Fig. 2. Comparison of gas-phase concentrations of a variety of carbonyls $\left(\leq \mathrm{C}_{6}\right)$ simulated with PTM-MCM for the 6 August event in this study, with those simulated with PTM-MCM by Utembe et al. (2005).

presented in Table 2 of Utembe et al. (2005). The total simulated carbonyl concentration (in ppt by volume) is a factor of ca. 1.5 greater in the present study, which can be related to the increased input and degradation of biogenic VOC. Whereas much of this additional concentration is manifested as increases in the concentrations of small carbonyls (especially formaldehyde and acetone), about $5 \%$ of the increase is due to notable elevations in the simulated concentrations of specific biogenic degradation products (e.g. methacrolein and methylvinyl ketone from isoprene; pinonaldehyde from $\alpha$-pinene; nopinone from $\beta$-pinene).
Although there is an increase in the total simulated carbonyl concentration, it is clear from Fig. 2 that there are changes in the simulated distribution, with both increases and decreases in the concentrations of specific species. With the exception of formaldehyde, the other seven species identified in the figure are those for which a model-measurement comparison was reported by Utembe et al. (2005). In that study, it was noted that the simulated concentrations of the aldehydes were systematically lower than observed, whereas the simulated concentrations of the ketones (with the exception of acetone) were systematically higher than observed. Although the discrepancies cannot be fully reconciled, the present simulations lead to an improved agreement in the model-measurement comparison for all seven species for the 6 August case study, by virtue of increases in the simulated concentrations of acetaldehyde, butanal, pentanal, hexanal and acetone, and decreases for butanone and 3-methylbutanone. Although there are almost certainly a number of contributing factors, the general influence of temperature on the competition between alkoxy radical decomposition reactions and their reactions with $\mathrm{O}_{2}$ plays a notable role, the former reactions being strongly temperaturedependent (e.g., Johnson et al., 2004b). As discussed previously (Utembe et al., 2005), the oxidation of the most abundant emitted anthropogenic VOC, butane, provides a good example, because it is a major source of butanone and also generates acetaldehyde. As a direct result of the competition between decomposition and reaction with $\mathrm{O}_{2}$ for 2butoxy radicals, the simulated yield of butanone from butane 


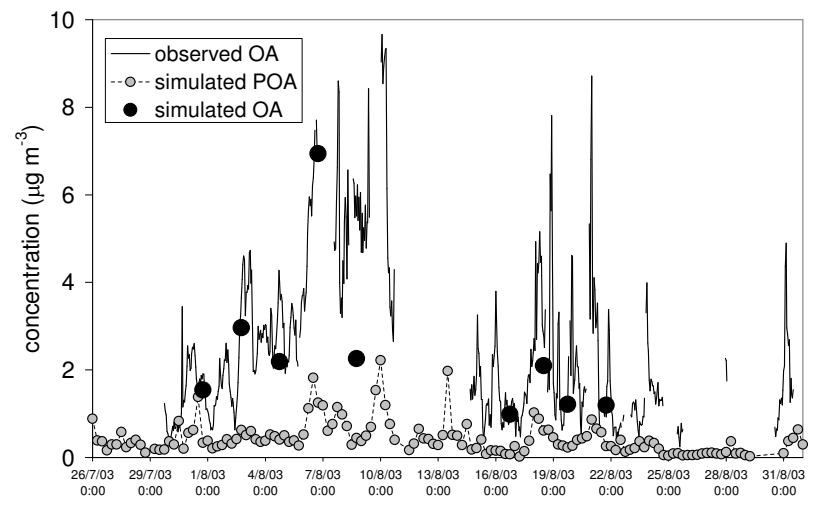

Fig. 3. Comparison of observed hourly mean organic aerosol (OA) mass concentrations (line) with those simulated. Filled grey circles: simulated mass concentrations of primary organic aerosol (POA). Filled black circles: simulated total OA mass concentration for the nine case study events, optimised as described in the text.

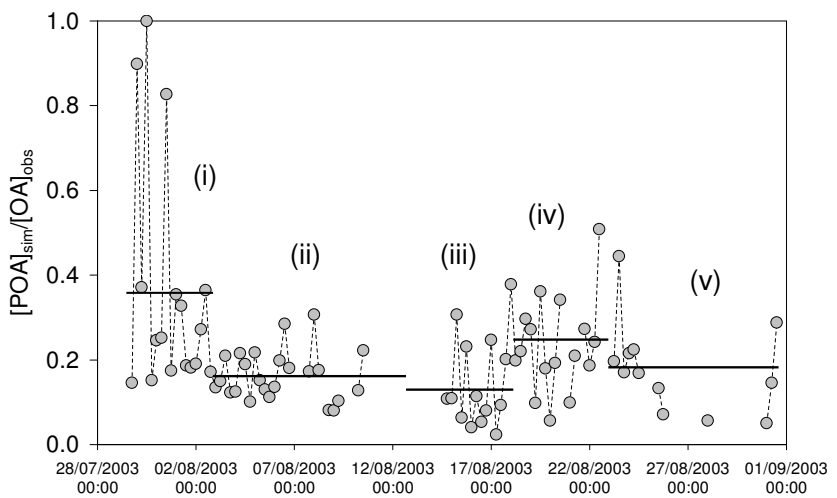

Fig. 4. Ratio of simulated primary organic aerosol (POA) mass concentration to total organic aerosol (OA) mass concentration. The broken line joining the points is to guide the eye, and is not intended to infer intermediate simulated values. The horizontal lines represent average ratios for the five broad meteorological periods during the campaign (see Sect. 2).

oxidation in MCM v3.1 falls from ca. $70 \%$ at $298 \mathrm{~K}$ to ca. $60 \%$ at $308 \mathrm{~K}$, whereas the yield of acetaldehyde increases from ca. $15 \%$ to ca. $30 \%$ over the same temperature range.

\subsection{Simulations of primary organic aerosol}

The PTM-CRI simulations also allowed mass concentrations of POA to be simulated at six-hourly intervals for the whole campaign, which are compared with the observed OA mass loadings in Fig. 3. The observed concentrations were derived from those reported by McFiggans et al. (2005), and represent hourly mean mass loadings of sub-micron OA. The simulated POA concentrations were sensitive to air mass history, varying over the range $0.017-2.2 \mu \mathrm{g} \mathrm{m}^{-3}$. As shown in Fig. 4, the simulated POA concentrations did not exceed the observed OA mass loadings, but accounted for variable

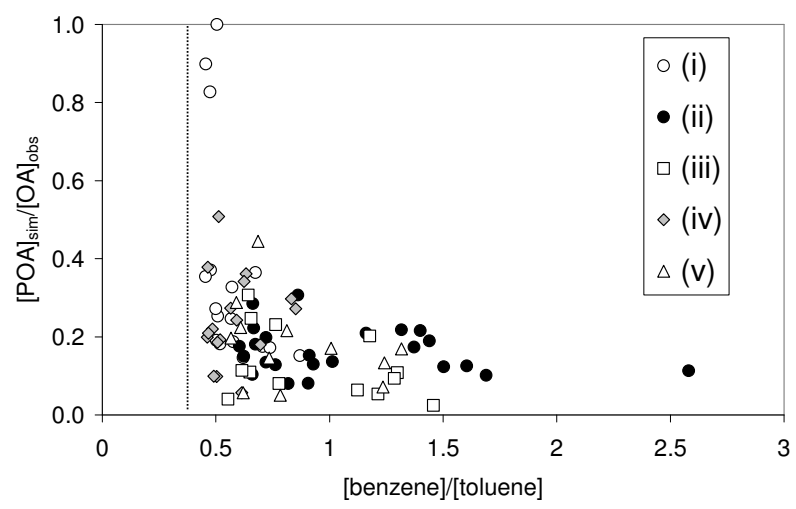

Fig. 5. Dependence of the data plotted in Fig. 3 on extent of chemical processing, as represented by the simulated [benzene]/[toluene] ratio. Data are distinguished for the five broad meteorological periods during the campaign (see Sect. 2). The vertical broken line represents the benzene/toluene emission ratio in the model.

proportions of the total. The largest average POA contribution inferred by these calculations (36\%) occurred during period (i), when the campaign site was frequently situated in the London plume and therefore freshly polluted. Period (iv) also shows a comparatively high POA contribution (24\% on average), this period being dominated by westerly winds with the site occasionally in the London plume. For the remainder of the campaign, lower contributions are apparent, because the conditions were either dominated by comparatively unpolluted aged air arriving from the northerly sector (period (iii), 13\%; and period (v), 18\%), or stable anticyclonic conditions prevailed (period (ii), 16\%), during which the site received highly processed polluted air. The campaign mean contribution of the simulated POA to the observed OA (based on integrated loadings) is $18 \%$, which suggests that the large majority of the observed OA was not emitted directly, but formed from chemical processing of emitted VOC for the conditions of this campaign.

McFiggans et al. (2005) have recently used reproducible characteristics of the AMS spectra to determine contributions to the organic aerosol mass loadings made by un-oxidised and oxidised material for periods (i) and (ii) of the TORCH campaign, with these respective contributions referred to as "hydrocarbon-like organic aerosol (HOA)" and "oxidised organic aerosol (OOA)". Although it is recognised that these contributions are not necessarily synonymous with "POA" and "SOA", the ratios of simulated POA to observed OA in Fig. 4 show good consistency with the fractional contributions of HOA reported by McFiggans et al. (2005). Following the procedure of McFiggans et al. (2005), the present results are also plotted against the simulated [benzene]/[toluene] ratio in Fig. 5, to illustrate the dependence of the simulated POA contribution on the extent of air mass chemical processing. The clearly diminishing contribution of POA with increasing air mass processing agrees well with 
that reported for HOA by McFiggans et al. (2005), with a typical contribution of about $10 \%$ for the most processed air during the anticyclonic period (ii). The present analysis therefore suggests that HOA provides a reasonable measure of POA for the conditions of this campaign. It is noted that, if the methodology adopted here for representing POA emissions (based on AMS measurements of fine organic particulate mass, $\leq 200 \mathrm{~nm}$ ) misses a fraction of primary material of larger diameter, and that a fraction of POA is oxidised material, it is possible for a degree of compensation to occur leading to fortuitous agreement of the observed HOA and the simulated POA. Although this possibility cannot be entirely ruled out, it is also clear that the POA emissions cannot be increased greatly without the simulated POA concentrations exceeding the observed total $\mathrm{OA}$ concentrations for a number of events in period (i) of the campaign (Fig. 4).

\subsection{Simulations of secondary organic aerosol}

Concentrations of total OA mass were simulated for the nine selected events identified in Table 2, using the PTM-MCM with the representation of SOA formation, based on absorptive partitioning of lower volatility products of VOC oxidation described above in Sect. 4, in conjunction with POA emissions. Similarly to the chamber simulations of Jenkin (2004) and Johnson et al. (2004a, 2005), use of the partitioning coefficients $\left(K_{p}\right)$ estimated by this procedure resulted in simulation of negligible concentrations of SOA, and it was necessary to scale the values of $K_{p}$ by a factor of at least several hundred to generate concentrations of a comparable magnitude to those observed. These initial simulations also demonstrated that it was not possible to recreate the concentrations observed in the series of case studies using a consistent scaling factor, with events with lower OA concentrations generally requiring a greater amount of scaling. To force the simulated OA concentrations into general agreement with those observed it was therefore necessary to invoke three general sources, as follows:

- Source (i): POA resulting from direct emissions.

- Source (ii): A "ubiquitous" hourly-mean background concentration of OA of $0.7 \mu \mathrm{g} \mathrm{m}^{-3}$, represented as an initialisation of the model.

- Source (iii): The gas to aerosol transfer of lower volatility products of VOC oxidation generated by the regional scale processing of emitted VOC, represented as described in section 4, but with all $K_{p}$ values increased by a species-independent factor of 500 .

The background concentration and the scaling factor for the $K_{p}$ values were adjusted to optimise the agreement with the observed hourly-mean OA concentrations in the complete series of case studies (Table 2 and Fig. 3), leading to the values quoted above. The contributions of sources (ii) and (iii)

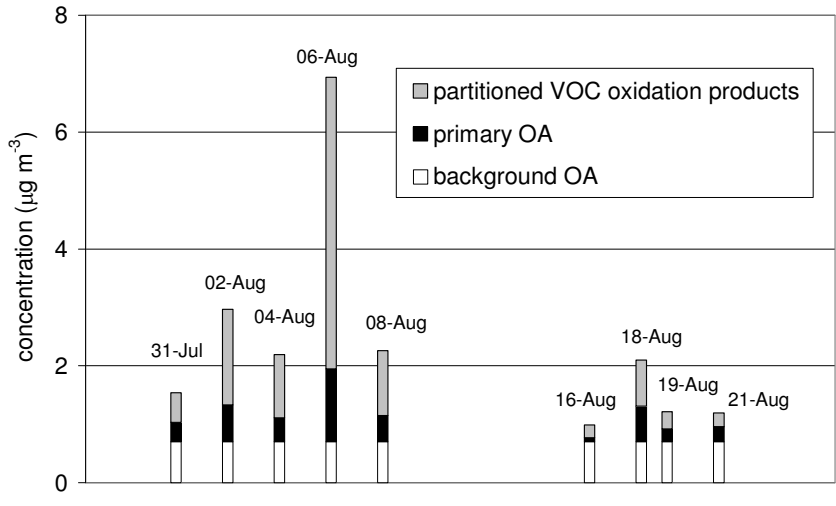

Fig. 6. Simulated contributions to organic aerosol for the nine case study events in Table 2: primary OA (source (i)), lower volatility VOC oxidation products (source (ii)) and background OA (source (iii)).

(which may be regarded collectively as 'SOA') are both indicative of the occurrence of chemical processes within the aerosol which allow the oxidised organic species to react by association and/or accretion reactions which generate even lower volatility products. Such processes are likely to be more important in acidic aerosols (e.g., Jang and Kamens, 2001b; Jang et al., 2002, 2005; Gao et al., 2005), and with prolonged timescales available for chemical processing. As a result, the thermodynamic equilibrium approach severely underestimates the transfer of organic material to the aerosol, and the scaling factor required to bring the simulations into agreement with observations is much greater than in the previous simulations of chamber data (Jenkin, 2004; Johnson et al., 2004a, 2005). The resultant non-volatile organic aerosol is therefore very persistent, leading to the 'ubiquitous' background concentration.

After optimisation, the simulated total OA concentration agrees well with observations for eight of the nine selected events (see Table 2 and Fig. 3). In common with the simulations of ozone described above (section 5.1), however, the total simulated OA concentration for the 8 August event is significantly lower than that observed (the fact that both OA and ozone are notably under-simulated for this case study, points to a common problem, most likely an underestimated emissions input in the model for this case study). Consequently, the methodology appears to provide a consistent description of the observed OA mass loading for a variety of conditions. As indicated in Table 2, the series of case studies covers more than an order of magnitude variation in the average emission rates for anthropogenic VOC and $\mathrm{NO}_{\mathrm{x}}\left(\mathrm{E}_{\mathrm{AVOC}}\right.$ and $\left.\mathrm{E}_{\mathrm{NO}_{\mathrm{x}}}\right)$ along the associated back-trajectories, variable contributions of biogenic VOC emission rates, $\mathrm{E}_{\mathrm{BVOC}}$ (between 3 and $15 \%$ relative to the anthropogenic VOC emissions), and a factor of ca. 2 variation in the relative emission rates of total VOC and $\mathrm{NO}_{\mathrm{x}}, \mathrm{E}_{\mathrm{VOC}} / \mathrm{E}_{\mathrm{NO}_{\mathrm{x}}}$, over the approximate range 0.7-1.5. 


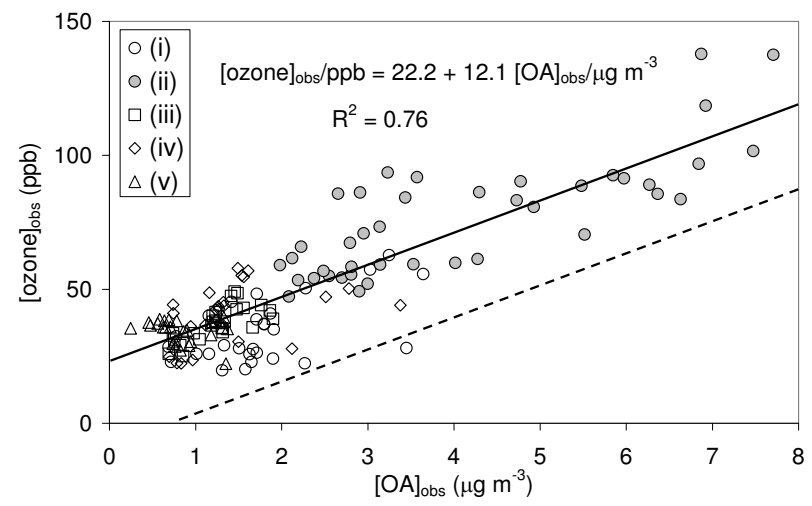

Fig. 7. Correlation between afternoon (12:00-18:00 h) hourly mean concentrations of ozone measured by the University of York (Utembe et al., 2005) and organic aerosol. Data are distinguished for the five broad meteorological periods during the campaign (see Sect. 2). The full line is a regression of all the data, with the relationship shown. The broken line is full line with a typical average August 12:00-18:00 h rural background ozone concentration of $31.7 \mathrm{ppb}$ subtracted (see text).

The contributions to OA made by the three general source categories are illustrated for the nine case study events in Fig. 6. During the height of the photochemical episode (6 August), the dominant contribution (72\%) to the simulated OA results from regional scale VOC processing, source (iii), with the background and POA accounting for $10 \%$ and $18 \%$, respectively. For the case studies with the lowest [OA], the simulated concentration is dominated by the background contribution, source (ii), e.g., accounting for $71 \%$ of the total in the 16 August event. This clearly demonstrates the necessity for the background OA contribution in the simulations, because it is not only the dominant contributor under such conditions, but also provides a partitioning medium for the VOC oxidation products, which account for the majority of the remaining OA. Under intermediate conditions (e.g., 18 August), comparable contributions are made by all three sources.

Table 2 also shows the total mass concentration of VOC oxidation products (OP) simulated for each of the case study events, subdivided into concentrations of "semi-/nonvolatile" species with $T_{b} \geq 450 \mathrm{~K}$ (i.e., those for which phase partitioning was represented) and the remaining "volatile" species with $T_{b}<450 \mathrm{~K}$. Comparison with the concentrations of oxidation products simulated to be contributing to OA demonstrates that only 5.7-18.1\% (mean, 11.3\%) of the "semi-/non-volatile" material is simulated to be present in the condensed organic phase for the nine events. In each case, the mass concentration of "volatile" oxidation products is simulated to be greater than the "semi-/non-volatiles", by factors lying in the range 1.8-2.8. Consequently, only a small proportion (1.6-5.4\%: mean, 3.5\%) of the total oxidised organic material generated by regional scale VOC oxidation is simulated to be in the aerosol-phase, even though this material makes an important contribution to the OA mass loading.

A main implication of this work is that regional scale VOC oxidation processes are an important factor in the generation of OA, particularly during the anticyclonic period of the campaign (e.g., as represented by the 6 August event). Further support for this is provided by the strong correlation between observed ozone and OA concentrations presented in Fig. 7, since it is well established that elevated ozone concentrations in the UK are generated by regional scale VOC oxidation under anticyclonic conditions in north-west Europe (e.g., Derwent et al., 1996; Jenkin et al., 2002a). To avoid complications associated with ozone deposition from the shallow night-time boundary layer, Fig. 7 only presents data obtained during the hours ending 12:00-18:00 h (i.e., when the boundary layer depth is likely to be at, or close to, its maximum). Also shown in the figure is the effect of correcting the data for an appropriate average background ozone concentration. This is estimated to be $31.7 \mathrm{ppb}$, based on rural ozone data from the Wicken Fen site in Cambridgeshire $\left(52.30^{\circ} \mathrm{N} ; 0.29^{\circ} \mathrm{E}\right)^{2}$, for the hours ending $12: 00-18: 00 \mathrm{~h}$ in August 2002. During that month, there were only two minor regional scale photochemical events (in contrast to August 2003), the data for which were not included in the average. Subtraction of the background ozone concentration from the regression line in Fig. 7 generates a relationship which intercepts the $[\mathrm{OA}]$ axis at $0.78 \mu \mathrm{g} \mathrm{m}^{-3}$, consistent with the existence of an average background OA contribution of this magnitude, and with additional OA formation deriving from regional scale VOC oxidation (i.e., in common with ozone formation). Although the representative August afternoon background ozone concentration, and therefore the resultant [OA] intercept, is subject to some uncertainty, the complete absence of an [OA] intercept would require an average background ozone concentration of $22.2 \mathrm{ppb}$, which is unrealistically low for a rural location such as Writtle. Consequently, the correlation presented in Fig. 7 provides strong evidence for both an important role of regional scale VOC oxidation in generating $\mathrm{OA}$, and for the existence of a background $\mathrm{OA}$ concentration, and therefore supports the PTM-MCM analysis presented above. It should be noted, however, that the [OA] vs [ozone] relationship presented in Fig. 7 is only applicable for the conditions from which it is derived (i.e. August afternoon at comparable rural locations), and cannot be used as a general method of inferring OA concentrations.

Some further support for the existence of a nearly ubiquitous background fine OA concentration of the order of $1 \mu \mathrm{g} \mathrm{m}^{-3}$ comes from an increasing body of evidence

\footnotetext{
${ }^{2}$ The Wicken Fen site is part of the DEFRA Automatic Urban and Rural Network (AURN). It is a comparable UK rural site ca. 50 $\mathrm{km}$ north of Writtle, and is also located in an area of flat arable farmland, approximately $2 \mathrm{~km}$ from the nearest main road. The monitoring data employed are available from the UK Air Quality Archive, www.airquality.co.uk.
} 
derived from online compositional analyses at a number of locations (e.g., Allan et al., 2004; Topping et al., 2004; Coe et al., 2005). Of particular relevance to the present study are data from the North Atlantic Marine Boundary Layer Experiment (NAMBLEX) project, measured in clean air in the west of Ireland, which show median and 75th percentile organic loadings of this order (see Fig. 8 of Coe et al., 2005).

\subsection{Simulations of elemental and organic carbon}

As indicated above (Sect. 3.2 and Table 1), emissions of elemental carbon (EC) were represented in the model, such that the emitted ratio of organic carbon (OC) to elemental carbon (EC) was 1.1, consistent with the observed lower limit ratio reported by Castro et al. (1999). This resulted in simulated EC concentrations varying over the range 0.012 $1.7 \mu \mathrm{g} \mathrm{m}^{-3}$ for the entire campaign, and over the range 0.05 $0.95 \mu \mathrm{g} \mathrm{m}^{-3}$ for the nine case study events (see Table 2 and Fig. 8). The contribution of secondary organic material to the simulated OA results in significant elevations in $[\mathrm{OC}] /[\mathrm{EC}]$. The compositional analysis presented in the companion paper (Johnson et al., 2006), indicates that the partitioning VOC oxidation products in the $\mathrm{OA}$ are simulated to be made up of almost exactly 50\% carbon (by mass), with the balance being hydrogen, oxygen and nitrogen. Assuming this also applies to the OA background, $[\mathrm{OC}] /[\mathrm{EC}]$ is calculated to lie in the comparatively narrow range, $2.7-4.1$, for eight of the nine case studies (mean, 3.6), with the highest of these values applying to the 6 August event for which regional scale VOC processing makes the dominant contribution to $\mathrm{OA}$. In the case of the comparatively unpolluted 16 August event, the dominance of the background contribution to OA (Fig. 8 and Table 2) and the small contributions of the emitted carbonaceous components, leads to a substantially larger ratio of 9.8 (N.B. because of the background concentration of $0.7 \mu \mathrm{g} \mathrm{m}^{-3} \mathrm{OA}$, or $0.35 \mu \mathrm{g} \mathrm{m}^{-3} \mathrm{OC},[\mathrm{OC}] /[\mathrm{EC}]$ ratios are predicted to tend to infinity in clean air). The simulated values of $[\mathrm{OC}] /[\mathrm{EC}]$ for the conditions of this campaign are therefore generally close to, or in excess of, the high end of the range (ca. 3-4) reported by Castro et al. (1999) for summertime measurements at a background site in Birmingham.

\subsection{Discussion of elevation in $K_{p}$ values}

The results of the simulations presented above allow broad rationalisation of the observed OA mass loadings, and their variation from one case study to another. However, this can only be achieved if the values of $K_{p}$ for the partitioning products of VOC oxidation are increased by a very large scaling factor (i.e., 500) compared with those predicted by Eq. (3), based on estimated properties, by the method described in Sect. 4. This is interpreted as strong evidence for the occurrence of association and accretion reactions in the condensed organic phase, leading to the formation of products of substantially lower volatility. It is recognised, however,

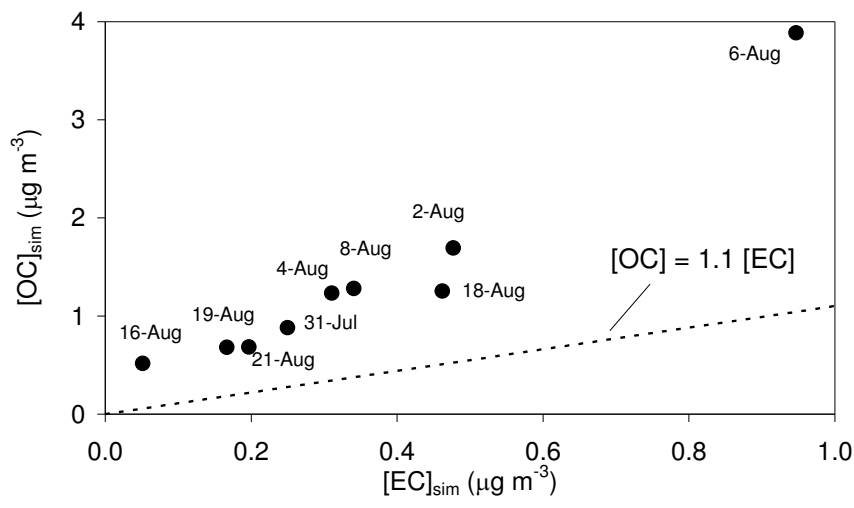

Fig. 8. Simulated concentrations of organic carbon, $[\mathrm{OC}]_{\mathrm{sim}}$, and elemental carbon, $[\mathrm{EC}]_{\text {sim }}$, for the nine case study events in Table 2. The broken line represents the ratio applied to the emitted carbonaceous aerosol.

that other model uncertainties may potentially contribute to systematic errors in the simulated OA mass loadings, and that the net effect of these additional factors may also influence the magnitude of the required elevation in $K_{p}$ values. These additional factors fall broadly into two categories: first, those which influence the simulated quantity of oxidised organic material; and, second, those which lead to uncertainties in the application of Eq. (3), e.g., resulting from possible errors in the estimated values of $p_{L}^{\circ}$, or from deviations from the assumed ideality of the absorbing condensed phase.

\subsubsection{Simulated quantity of oxidised organic material}

The simulated concentration of VOC oxidation products is determined by a combination of air mass history, magnitude and speciation of VOC emissions, and the extent of their chemical processing prior to arrival at the campaign site. The combination of trajectories, mapped emissions and chemical degradation applied in the present work gives an acceptable general description of the observations for the conditions of this campaign, and there is a high level of consistency with regard to a number of key observations. The model-measurement comparisons described previously by Utembe et al. (2005) for the TORCH campaign indicate that the quantity and speciation of emitted anthropogenic VOC are well described throughout the campaign, with particularly good agreement for the aromatic hydrocarbons which, as described in the companion paper (Johnson et al., 2006), are important SOA precursors. In addition, the simulated POA concentrations presented and discussed in Sect. 5.2 are in very good agreement with the HOA observations of McFiggans et al. (2005), also suggesting a good quantification of integrated pollutant input prior to air mass arrival, and its variation with meteorological conditions. The distributions of light carbonyl compounds simulated with the PTMMCM for the TORCH case studies described by Utembe et 
al. (2005), and above in Sect. 5.1, also indicate that the extent of chemical processing is consistent with observations. The results are in general agreement with summertime carbonyl distributions available in the literature for the UK, measured as part of the EMEP network (e.g., Solberg et al., 1996), and, where comparison is possible, also in reasonable accord with the measurements made in the TORCH campaign (Utembe et al., 2005).

The good agreement in these observations is partly indicative that the input of anthropogenic pollutants is well described in the model. Indeed, the uncertainty in the UK emission totals for anthropogenic $\mathrm{VOC}$ and $\mathrm{NO}_{\mathrm{x}}$ have recently been estimated to be a low as $\pm 8 \%$ (AQEG, 2004, 2005). In contrast, biogenic VOC emissions are subject to much greater uncertainty. For example, Stewart et al. (2003) have estimated an uncertainty of a factor of \pm 4 in total emissions of isoprene and monoterpenes in Great Britain, defined using a similar approach to that adopted in the present study. The impact of an under-representation of this magnitude therefore needs to be assessed. As described in more detail in the companion paper (Johnson et al., 2006), the products of biogenic VOC oxidation are simulated to account for between ca. $16 \%$ and $50 \%$ of the partitioning oxidation products in the nine case studies (corresponding to between ca. 5\% and $20 \%$ of the total simulated OA). Consequently, increasing the biogenic VOC emissions input by a factor of four (i.e. to the top end of the uncertainty range) would lead to increases in the simulated total concentrations of partitioning oxidation products by factors of between ca. 1.5 and 2.5 (depending on the case study), and the need to reduce the $K_{p}$ scaling factor by corresponding amounts to match the observations. However, even under such circumstances, the $K_{p}$ scaling factor would still need to be between ca. 200 and 330 (depending on the case study), such that the qualitative conclusion concerning the need for substantial scaling (and the likely occurrence of condensed phase accretion reactions) would remain unchanged.

\subsubsection{Calculation of $\mathrm{K}_{p}$ values}

The $K_{p}$ values calculated using Eq. (3) make use of vapour pressures estimated for the series of partitioning species, and also depend on assumptions about the nature and composition of the absorbing aerosol-phase, which can influence the activity coefficients of the partitioning species, $\zeta$, and the average molecular weight of the absorbing medium, $M W_{\text {om }}$. Possible uncertainties in the estimated properties and the implications of assuming that the condensed phase mixture is ideal (i.e., $\zeta=1$ ) therefore need to be assessed.

As described in more detail in the companion paper (Johnson et al., 2006), the VOC oxidation products contributing significantly to the aerosol-phase are simulated to be a variety of complex multifunctional oxygenated species, typically containing subset combinations of nitrate, nitro, carbonyl, hydroxy, hydroperoxy, acid and anhydride functional groups. It is therefore not possible to compare estimated data for such species with measurements, because the latter are not available. However, some discussion of the general uncertainties in the species vapour pressures has been provided previously by Johnson et al. (2005), relating particularly to the estimation of boiling temperatures by the method of Stein and Brown (1994). The estimated boiling temperatures for a variety of substituted aromatic species (i.e., nitrated benzenes, phenols and nitrated phenols) were found to compare well with measurements (i.e. to within ca. $\pm 20 \mathrm{~K}$ ), where available. This is indicative of a typical uncertainty in $p_{L}^{\circ}$ of within a factor of ca. \pm 3 for an individual species, with the average over a large number of partitioning species expected to be lower than this.

The Pankow equilibrium absorption model represents the partitioning of organic molecules between the gaseous phase and the condensed (liquid) organic phase. The use of a unity value of $\zeta$ (adopted in the present study and elsewhere) is justifiable for a species partitioning into a condensed phase of similar species, with deviations occurring if the partitioning species is dissimilar to the overall mixture (e.g., the initial partitioning of a multifunctional oxidised species into a predominantly primary, hydrocarbon-like aerosol). For example, this latter case would be expected to result in a $\zeta$ value which is greater than 1 for such a species, and an associated reduced tendency to partition into the condensed phase (i.e. a reduction in $K_{p}$ for that species). Activity coefficients have been estimated for a variety of organic aerosol components in a number of studies (e.g., Jang et al., 1997; Jang and Kamens, 1998; Seinfeld et al., 2001; Bowman and Melton, 2004). For example, Jang et al. (1997) and Jang and Kamens (1998) calculated values of $\zeta$ lying in the approximate range 0.3-200, but with values $>10$ only occurring for when the partitioning species is highly dissimilar to absorbing medium. As described above in Sect. 5.2, the organic aerosol mixtures characterised in the TORCH 2003 campaign were composed predominantly of secondary organic material (accounting for ca. $80 \%$ on average), suggesting that use of a unity value of $\zeta$ is not an unreasonable assumption. It should also be noted that values of $\zeta$ greater than 1 would require further increased scaling in the associated $K_{p}$ values to force the simulated OA concentrations into agreement with those observed.

Also of significance to simulations of ambient conditions, however, are possible influences of the presence of water on the transfer of organic material from the gaseous to the condensed organic phase. In addition to increasing the total mass concentration of the absorbing OA phase, the presence of water also potentially influences values of $K_{p}$ calculated from Eq. (3) through its (varying) impacts on $\zeta$ for the partitioning organic species, and through its effect on the number-average molecular weight of the absorbing OA phase. Some discussion of these effects has been given in the review article of Seinfeld and Pankow (2003), who proposed the following expression for the influence of relative humidity $(\mathrm{RH})$ upon 
values of $K_{p}$ :

$\frac{d K_{p}}{d R H}=-K_{p} \frac{d \ln M W_{o m}}{d R H}-K_{p} \frac{d \ln \varsigma}{d R H}$

In their appraisal of SOA formation from monoterpenes (which should also be generally applicable to other SOA precursor VOC), Seinfeld and Pankow (2003) concluded that $d K_{p} / d \mathrm{RH}$ is positive for all compounds considered, and that this is mainly due to the low molecular weight of water compared to those of the organic oxidation products in the condensed phase, i.e. the presence of water lowers the average molecular weight, leading to a uniform increase in the value of $K_{p}$ for all partitioning species, as described by the first term in Eq. (7). The effect of RH on $\zeta$ is more complex, with a range of positive and negative values of $d \ln \zeta / d R \mathrm{H}$ possible, depending on the hydrophobicity or hydrophilicity of the partitioning species. However, as discussed by Seinfeld et al. (2001), $\zeta$ values are predicted to vary only weakly with RH for many compounds contributing to SOA, such that this is a second order effect compared with the influence on molecular weight. The likely magnitude of the general increasing influence of water on $K_{p}$ values can be estimated from measurements of SOA growth factors, which are typically ca. 1.1, based on the increase in diameter at ca. $90 \% \mathrm{RH}$ (e.g., Virkkula et al., 1999; Cocker et al., 2001; McFiggans et al., 2005). This suggests that no more than ca. $25 \%$ of the volume of the OA phase can be attributed to water, such that the corresponding decrease in average molecular weight (and increase in $K_{p}$ values) is comparatively modest (i.e. $\leq$ a factor of ca. 3 for organic material of average molecular weight $170)$.

The above considerations relate specifically to the partitioning of organic species into a condensed phase mainly comprised of organic material. It is recognised that the ambient aerosol is a mixed organic-inorganic aerosol, and that the total water content is likely to be considerably greater by virtue of the hygroscopicity of the inorganic components. Indeed, the measurements reported by McFiggans et al. (2005) indicate typical growth factors of ca. 1.4-1.6 at $90 \% \mathrm{RH}$ for the TORCH campaign, consistent with a deliquesced aerosol at high relative humidities, with water as the major component (by volume). It is therefore possible that enhanced uptake of water soluble organics (i.e., by dissolution into the aqueous phase, characterised by Henry's Law coefficients) may contribute to the requirement to scale significantly the values of $K_{p}$. It is also recognised that the rates of condensed phase chemical reactions of partitioned organics are likely to depend on water content, with the rates of a variety of proposed processes either increasing or decreasing. A full appraisal of these factors is outside the scope of the present modelling study, but it is a major consideration of ongoing work.

The above discussions indicate that systematic uncertainties in a number of factors can potentially influence (i.e. increase or decrease) the concentrations of OA simulated in the present study. Although enhanced uptake of water soluble organics may play a role, it is difficult to account for the very large and consistent scaling factor for the $K_{p}$ values (required to match the observations) without also invoking an important role for condensed phase accretion chemistry, which generates products of higher molecular weight and much lower volatility. As discussed in more detail in the companion paper (Johnson et al., 2006), this conclusion is entirely consistent with the observation of oligomeric, humic-like substances in a number of recent studies of OA in chambers (Kalberer et al., 2004; Tolocka et al., 2004) and in the atmosphere (Samburova et al., 2005).

\section{Summary and conclusions}

A photochemical trajectory model (PTM) has been used to simulate the chemical evolution of boundary layer air masses arriving at a field campaign site in the southern UK during late July and August 2003, a period which included a widespread and prolonged photochemical pollution episode. The model incorporates speciated emissions of 124 nonmethane anthropogenic VOC and three representative biogenic VOC (isoprene, $\alpha$-pinene and $\beta$-pinene), coupled with a comprehensive description of their degradation chemistry, provided by either the Master Chemical Mechanism (MCM v3.1) or the Common Representative Intermediates (CRI) mechanism. A representation of the gas-aerosol partitioning of ca. 2000 oxygenated organic species generated in MCM v3.1. has been developed and implemented, based on the absorptive partitioning methodology of Pankow (1994), allowing simulation of the contribution to organic aerosol made by semi- and non-volatile products of VOC oxidation; emissions of carbonaceous aerosols (POA and EC) are also represented.

The simulated mass concentrations of POA account for variable fractions of the observed $\mathrm{OA}$, and demonstrate a clearly diminishing contribution with increasing extent of air mass processing, as quantified by the simulated [benzene]/[toluene]. The campaign mean contribution (based on integrated loadings) is $18 \%$, which indicates that the large majority of the observed OA was not emitted directly, but formed from chemical processing of emitted VOC for the conditions of this campaign.

Simulations of total OA mass concentrations in nine case study events (optimised by comparison with the observed mass loadings) imply that the OA can be ascribed to three general sources, as follows: (i) POA resulting from direct emissions; (ii) a "ubiquitous" hourly-mean background concentration of $\mathrm{OA}$ of $0.7 \mu \mathrm{g} \mathrm{m}^{-3}$; and (iii) gas to aerosol transfer of lower volatility products of VOC oxidation generated by the regional scale processing of emitted VOC, but with all gas-aerosol partitioning coefficients increased by a species-independent factor of 500 . The requirement to scale the partitioning coefficients, and the implied background concentration, are both indicative of the occurrence 
of chemical processes within the aerosol which allow the oxidised organic species to react by association and/or accretion reactions which generate even lower volatility products leading to a persistent, non-volatile SOA. However, despite the large elevation of the partitioning parameters, analysis of the nine case study events suggests that only a small fraction (1.6-5.4\%: mean, 3.5\%) of the total oxidised organic material generated by regional scale VOC oxidation is simulated to be in the aerosol-phase, even though this material makes an important contribution to the OA mass loading.

A main implication of this work is that regional scale VOC oxidation processes are an important factor in the generation of OA. A strong correlation between observed afternoon ozone and OA concentrations throughout the campaign provide further support for this conclusion, and is indicative of regional scale VOC oxidation leading to the elevations in the concentrations of both ozone and OA during the anticyclonic period of the campaign.

The contribution of secondary organic material to the simulated OA results in significant elevations in simulated $[\mathrm{OC}] /[\mathrm{EC}]$, compared with the ratio of 1.1 assigned to the emitted carbonaceous aerosol. For the nine case study events, $[\mathrm{OC}] /[\mathrm{EC}]$ is calculated to lie in the range $2.7-9.8$, values which are comparable with the high end of the range reported in the literature. The highest ratios correspond to conditions when the dominant contribution to $\mathrm{OA}$ is either made by products of regional scale VOC oxidation (i.e. during the anticyclonic period of the campaign), or made by the background in comparatively unpolluted aged air arriving from the North Sea.

Acknowledgements. The work described in this paper was funded by the Natural Environment Research Council, (NERC), as part of the Tropospheric Organic Chemistry Experiment (TORCH) under contracts NER/T/S2002/00494 and NER/T/S2002/00495, and by the Department for Environment, Food and Rural Affairs (DEFRA) under contract EPG 1/3/200. M. E. Jenkin also acknowledges NERC for support via a Senior Research Fellowship (NER/K/S/2000/00870). The authors also gratefully acknowledge the following members of the TORCH consortium institutes: C. Bloss, A. Rickard and M. Pilling (University of Leeds) for ongoing collaboration on MCM development; A. Lewis, J. Hopkins, J. Hamilton and J. Lee (University of York) for provision of data on gas-phase organics and ozone, and for helpful discussions; and S. Clegg and X. Xu (University of East Anglia) for helpful discussions on prediction methods for boiling points and vapour pressures.

Edited by: F. J. Dentener

\section{References}

Alfarra, M. R.: Insights into atmospheric organic aerosols using an aerosol mass spectrometer, Ph.D. Thesis, University of Manchester, 2004.

Allan, J. D., Alfarra, M. R., Bower, K. N., Williams, P. I., Gallagher, M. W., Jimenez, J. L., McDonald, A. G., Nemitz, E., Canagaratna, M. R., Jayne, J. T., Coe, H. and Worsnop, D. R.: Quantitative Sampling Using an Aerodyne Aerosol Mass Spectrometer - 2. Measurements of Fine Particulate Chemical Composition in Two U.K. Cities, J. Geophys. Res., 108 (D3), 4091, doi:10.1029/2002JD002359, 2003.

Allan, J. D., Bower K. N., Coe H., Boudries H., Jayne J. T., Canagaratna M. R., Millet D. B., Goldstein A. H., Quinn P. K., Weber R. J., and Worsnop D. R.: Submicron aerosol composition at Trinidad Head, California during ITCT 2K2: its relationship with gas phase volatile organic carbon and assessment of instrument performance, J. Geophys. Res., 109, D23S24, doi:10.1029/2003JD004208, 2004.

AQEG.: Nitrogen dioxide in the United Kingdom. Report of the UK Air Quality Expert Group. Prepared at the request of the Department for Environment Food and Rural Affairs, London, PB9025, 2004.

AQEG.: Particulate matter in the United Kingdom. Report of the UK Air Quality Expert Group. Prepared at the request of the Department for Environment Food and Rural Affairs, London, PB10580 ISBN 0-85521-143-1, 2005.

Atkinson, R.: Atmospheric chemistry of VOCs and $\mathrm{NO}_{\mathrm{x}}$, Atmos. Environ., 34, 2063-2101, 2000.

Baum, E. J.: Chemical property estimation: theory and application, CRC Press, Florida, ISBN 0-87371-938-7, 1998.

Bloss, C., Wagner, V., Jenkin, M. E., Volkamer, R., Bloss, W. J., Lee, J. D., Heard, D. E., Wirtz, K., Martin-Reviejo, M., Rea, G., Wenger, J. C. and Pilling, M. J.: Development of a detailed chemical mechanism (MCMv3.1) for the atmospheric oxidation of aromatic hydrocarbons, Atmos. Chem. Phys., 5, 641644, 2005, SRef-ID: 1680-7324/acp/2005-5-641.

Boissard, C., Cao, X. -L., Juan, C. -Y., Hewitt, C. N. and Gallagher, M.: Seasonal variations in VOC emission rates from gorse, Atmos. Environ., 35, 917-927, 2001.

Bowman, F. M. and Melton, J. A.: Effect of activity coefficient models on predictions of secondary organic aerosol partitioning, Aerosol Science, 35, 1415-1438, 2004.

Cambridgesoft: ChemDraw Ultra version 7.0.1, Cambridge, MA, 2002.

Castro, L. M., Pio, C. A., Harrison, R. M., and Smith, D. J. T.: Carbonaceous aerosol in urban and rural European atmospheres: estimation of secondary organic carbon concentrations, Atmos. Environ., 33, 2771-2781, 1999.

Cocker, D. R., Clegg, S. L., Flagan, R. C., and Seinfeld, J. H.: The effect of water on gas-particle partitioning of secondary organic aerosol. Part I: $\alpha$-pinene/ozone system, Atmos. Environ., 35, 6049-6072, 2001.

Coe, H., Allan, J. D., Alfarra, M. R., Bower, K. N., Flynn, M. J., McFiggans, G., Topping, D. O., Williams, P. I., O’Dowd, C. D., Dall'Osto, M., Beddows, D. C. S., and Harrison, R. M.: Chemical and physical characteristics of aerosol particles at a remote coastal location, Mace Head, Ireland, during NAMBLEX, Atmos. Chem. Phys. Discuss., 5, 11 643-11 678, 2005

SRef-ID: 1680-7375/acpd/2005-5-11643. 
Derwent, R. G., Jenkin, M. E, and Saunders, S. M.: Photochemical ozone creation potentials for a large number of reactive hydrocarbons under European conditions, Atmos. Environ., 30, 181-199, 1996.

Derwent, R. G., Jenkin, M. E., Saunders, S. M., and Pilling, M. J.: Photochemical ozone creation potentials for organic compounds in North West Europe calculated with a master chemical mechanism, Atmos. Environ., 32, 2429-2441, 1998.

Dore, C., Hayman, G., Scholefield, P., Hewitt, N., Winiwarter, W., and Kressler, F.: Mapping of biogenic VOC emissions in England and Wales, Environment Agency R\&D Technical Report E1-122/TR, ISBN 1-84432-092-8, 2003a.

Dore, C. J., Goodwin, J. W. L., Watterson, J. D., Murrells, T. P, Passant, N. R, Hobson, M. M, Haigh, K. E., Baggott, G., Thistlethwaite, G., Pye, S. T., Coleman, P. J., King, K. R.: UK Emissions of Air Pollutants 1970-2001. National Atmospheric Emissions Inventory Report, AEAT/ENV/R/1593, ISBN 1-85580-033-0, $2003 b$.

Finlayson-Pitts, B. J. and Pitts, J. N.: Chemistry of the upper and lower atmosphere: theory, experiments and applications, Academic Press, 1999.

Gao, S., Ng, N. L., Keywood, M., Varutbangkul, V., Bahreini, R., Nenes, A., He, J., Yoo, K.Y., Beauchamp, J. L., Hodyss, R. P., Flagan, R. C., and Seinfeld, J. H.: Particle phase acidity and oligomer formation in secondary organic aerosol, Environ. Sci. Technol., 39, 6582-6589, 2005.

Goodwin, J. W. L., Salway, A. G., Murrells, T. P., Dore, C. J., Passant, N. R., King, K. R., Coleman, P. J., Hobson, M. M., Pye, S. T. and Watterson, J. D.: UK Emissions of air pollutants 1970-1999, National Atmospheric Emissions Inventory Report, AEAT/ENV/R/0798, ISBN 1-85580-031 4., 2001.

Guenther, A., Hewitt, C. N., Erickson, D., Fall, R., Geron, C., Graedel, T., Harley, P., Klinger, L., Lerdau, M., McKay, W.A., Pierce, T., Scholes, B., Steinbrecher, R., Tallamraju, R., Taylor, J., and Zimmerman, P.: A global model of natural volatile organic compound emissions, J. Geophys. Res., 100, 8873-8892, 1995.

Hartmann, D. L.: Global Physical Climatology, Academic Press, p. 3, 1994

He, C., Murray, F., and Lyons, T. : Monoterpene and isoprene emissions from 15 Eucalyptus species in Australia, Atmos. Environ., 34, 645-655, 2000.

Jang, M. and Kamens, R. M.: A thermodynamic approach for modelling partitioning of semivolatile organic compounds on atmospheric particulate matter: humidity effects, Environ. Sci. Technnol., 32, 1237-1243, 1998 .

Jang, M. S. and Kamens, R. M.: Characterization of secondary aerosol from the photooxidation of toluene in the presence of $\mathrm{NO}_{\mathrm{x}}$ and 1-propene, Environ. Sci. Technol., 35, 3626-3639, 2001a.

Jang, M. and Kamens, R. M.: Atmospheric secondary organic aerosol formation by heterogeneous reactions of aldehydes in the presence of sulphuric acid aerosol catalyst, Environ. Sci. Technnol., 35, 4758-4766, $2001 \mathrm{~b}$.

Jang, M., Kamens, R. M., Leach, K. B., and Strommen, M. R.: A thermodynamic approach using group contribution methods to model the partitioning of semivolatile organic compounds on atmospheric particulate matter, Environ. Sci. Technnol., 31, 28052811, 1997.
Jang, M., Czoschke, N. M., Lee, S., and Kamens, R. M.: Heterogeneous atmospheric aerosol production by acid-catalyzed particlephase reactions, Science, 298, 814-817, 2002.

Jang, M., Czoschke, N. M., and Northcross, A. L.: Semiempirical model for organic aerosol growth by acid-catalyzed heterogeneous reactions of organic carbonyls, Environ. Sci. Technnol., 39, 164-174, 2005.

Janson, R., Rosman, K., Karlsson, A., and Hansson, H.-C.: Biogenic emissions and gaseous precursors to forest aerosols, Tellus 53B, 423-440, 2001

Jenkin, M. E.: Modelling the formation and composition of secondary organic aerosol from $\alpha$ - and $\beta$-pinene ozonlysis using MCM v3, Atmos. Chem. Phys., 4, 1741-1757, 2004, SRef-ID: 1680-7324/acp/2004-4-1741.

Jenkin, M. E. and Clemitshaw, K. C.: Ozone and other secondary photochemical pollutants: chemical processes governing their formation in the planetary boundary layer, Atmos. Environ., 34, 2499-2527, 2000.

Jenkin, M. E., Saunders, S. M., and Pilling, M. J.: The tropospheric degradation of volatile organic compounds: a protocol for mechanism development, Atmos. Environ., 31, 81-104, 1997.

Jenkin, M. E., Murrells, T. P., and Passant, N. R.: The temporal dependence of ozone precursor emissions: estimation and application, AEA Technology report AEAT/R/ENV/0355, 2000.

Jenkin, M. E., Davies, T. J., and Stedman, J. R.: The origin and day-of-week dependence of photochemical episodes in the UK, Atmos. Environ., 36, 999-1012, 2002a.

Jenkin, M. E., Saunders, S. M., Derwent, R. G., and Pilling, M. J.: Development of a reduced speciated VOC degradation mechanism for use in ozone models, Atmos. Environ., 36, 4725-4734, $2002 b$

Jenkin, M. E., Saunders, S. M., Wagner, V., and Pilling, M. J.: Protocol for the development of the Master Chemical Mechanism, MCM v3 (Part B): tropospheric degradation of aromatic volatile organic compounds, Atmos. Chem. Phys., 3, 181-193, 2003, SRef-ID: 1680-7324/acp/2003-3-181.

Joback, K. G. and Reid, R. C: Estimation of pure-component properties from group-contributions, Chem. Eng. Commun., 57, 233243, 1987.

Johnson, D., Jenkin, M. E., Wirtz, K., and Martin-Reviejo, M.: Simulating the formation of secondary organic aerosol from the photooxidation of toluene, Environ. Chem., 1, 150-165, 2004a.

Johnson, D., Cassanelli, P., and Cox, R. A.: Correlation-type structure activity relationships for the kinetics of the decomposition of simple and $\beta$-substituted alkoxyl radicals, Atmos. Environ., 38, $1755-1765,2004 b$

Johnson, D., Jenkin, M. E., Wirtz, K., and Martin-Reviejo, M.: Simulating the formation of secondary organic aerosol from the photooxidation of aromatic hydrocarbons, Environ. Chem., 2, 3548,2005

Johnson, D., Utembe S. R., and Jenkin, M. E.: Simulating the detailed chemical composition of secondary organic aerosol formed on a regional scale during the TORCH 2003 campaign in the southern UK, Atmos. Chem. Phys., 6, 419-431, 2006 , SRef-ID: 1680-7324/acp/2006-6-419.

Kalberer, M., Paulsen, D., Sax, M., Steinbacher, M., Dommen, J., Prevot, A. S. H., Fisshea, R., Weingartner, E., Frankenvich, V., Zenobi, R., and Baltensperger, U.: Identification of polymers as major components of atmospheric organic aerosols, Science, 
303, 1659-1662, 2004.

Kamens, R. M., Jang, M., Chien, C.-J., and Leach, K.: Aerosol formation from the reaction of $\alpha$-pinene and ozone using a gasphase kinetics aerosol partitioning model, Environ. Sci. Technol., 33, 1430-1438, 1999.

Kanakidou, M., Seinfeld, J. H., Pandis, S. N., Barnes, I., Dentener, F. J., Facchini, M. C., Van Dingenen, R., Ervens, B., Nenes, A., Nielsen, C. J., Swietlicki, E., Putaud, J. P., Balkanski, Y., Fuzzi, S., Hjorth, J., Moortgat, G. K., Winterhalter, R., Myhre, C. E. L., Tsigaridis, K., Vignati, E., Stephanou, E. G. and Wilson, J.: Organic aerosol and global climate modelling: a review, Atmos. Chem. Phys., 5, 1053-1123, 2005,

SRef-ID: 1680-7324/acp/2005-5-1053

Leighton, P. A.: Photochemistry of air pollution, Academic Press, New York, 1961.

Llusia, J. and Peñuelas, J.: Seasonal patterns of terpene content and emission from seven Mediterranean woody species in field conditions, Amer. J. Botany, 87, 133-140, 2000.

McFiggans, G., Alfarra, M. R., Allan, J., Bower, K., Coe, H., Cubison, M., Topping, D., Williams, P., Descari, S., Facchini, C., and Fuzzi, S.: Simplification of the representation of the organic component of atmospheric particulates, Faraday Discuss., 130, 341-362, 2005.

Odum, J. R., Hoffmann, T., Bowman, F., Collins, D., Flagan, R. C., and Seinfeld, J. H.: Gas/particle partitioning and secondary organic aerosol yields, Environ. Sci. Technol., 30, 2580-2585, 1996.

Olivier, J. G. J., Bouwman, A. F., Van der Maas, C. W. M., Berdowski, J. J. M., Veldt, C., Bloos, J. P. J., Visschedijk, A. J. H., Zandveld, P. Y. J. and Haverlag, J. L.: Description of EDGAR Version 2.0: A set of global emission inventories of greenhouse gases and ozone-depleting substances for all anthropogenic and most natural sources on a per country basis and on $1^{\circ} \times 1^{\circ}$ grid. National Institute of Public Health and the Environment (RIVM), Bilthoven. Report no. 771060 002/TNO-MEP report no. R96/119, 1996.

Owen, S. M., Boissard, C., and Hewitt, C. N.: Volatile organic compounds (VOCs) emitted from 40 Mediterranean plant species: VOC speciation and extrapolation to habitat scale, Atmos. Environ., 35, 5393-5409, 2001.

Pankow, J. F.: An absorption model of gas/particle partitioning involved in the formation of secondary organic aerosol, Atmos. Environ., 28, 189-193, 1994.

Penkett, S. A., Blake, N. J., Lightman, P., Marsh, A. R. W., Anwyl, P., and Butcher, G.: The seasonal variation of non-methane hydrocarbons in the free troposphere over the North Atlantic ocean : possible evidence for extensive reaction of hydrocarbons with the nitrate radical, J. Geophys. Res., 98, 2865-2885, 1993.

Samburova, V., Kalberer, M., and Zenobi, R.: Characterization of high molecular weight compounds in urban atmospheric particles, Atmos. Chem. Phys., 5, 2163-2170, 2005,

SRef-ID: 1680-7324/acp/2005-5-2163.
Saunders, S. M., Jenkin, M. E., Derwent, R. G., and Pilling, M. J.: Protocol for the development of the Master Chemical Mechanism, MCM v3 (Part A): tropospheric degradation of nonaromatic volatile organic compounds, Atmos. Chem. Phys., 3, 161-180, 2003,

\section{SRef-ID: 1680-7324/acp/2003-3-161}

Seinfeld, J. H. and Pankow, J. F.: Organic atmospheric particulate material, Ann. Rev. Phys. Chem., 54, 121-140, 2003.

Seinfeld, J. H., Erdakos, G. B., Asher, W. E., and Pankow, J. F: Modelling the formation of secondary organic aerosol (SOA). 2. The predicted effects of relative humidity on aerosol formation in the $\alpha$-pinene-, $\beta$,pinene-, sabinene-, $\Delta^{3}$-carene- and cyclohexene-ozone systems, Environ. Sci. Technol., 35, 18061817, 2001.

Solberg, S., Dye, C., and Schmidbauer, N.: VOC measurements 1994-1995, EMEP-CCC Report 6/96, Reference O92016, 1996.

Spänke, J., Rannik, U., Forkel, R., Nigge, W., and Hoffmann, T.: Emission fluxes and atmospheric degradation of monoterpenes above a boreal forest: field measurements and modelling, Tellus 53B, 406-422, 2001

Stein, S. E. and Brown, R. L.: Estimation of normal boiling points from group contributions, J. Chem. Info. Comp. Sci., 34, 581587, 1994.

Stewart, H. E., Hewitt, C. N., Bunce, R. G. H., Steinbrecher, R., Smiatec, G., and Schoenemeyer, T.: A highly spatially and temporally resolved inventory for biogenic isoprene and monoterpene emissions: Model description and application to Great Britain, J. Geophys. Res., 108, D20, 4644, doi:10.0129/2002JD002694, 2003.

TNO.: Particulate matter emissions $\left(\mathrm{PM}_{10}, \mathrm{PM}_{2.5}\right.$ and $\left.\mathrm{PM}_{0.1}\right)$ in Europe in 1990 and 1993, TNO Report TNO-MEP-R96-472, Netherlands, February 1997.

Tolocka, M. P., Jang, M., Ginter, J. M., Cox, F. J., Kamens, R. M., and Johnston, M. V.: Formation of oligomers in secondary organic aerosol, Environ. Sci. Technol., 38, 1428-1434, 2004.

Topping, D. O., Coe, H., McFiggans, G., Burgess, R. A., Allan, J. D., Alfarra, M. R., Bower, K. N., Choularton, T. W., Decesari, S., and Facchini, M.-C.: Aerosol chemical characteristics from sampling conducted on the Island of Jeju, Korea, during ACE Asia, Atmos. Env., 38, 2111-2123, 2004.

USEPA.: United States Environmental Protection Agency compilation of air pollutant emission factors, Vol. 1, 5th edition, AP-42, North Carolina, January 1995.

Utembe, S. R., Jenkin, M. E., Derwent, R. G., Lewis, A. C., Hopkins, J. R., and Hamilton, J. F.: Modelling the ambient distribution of organic compounds during the August 2003 ozone episode in the southern UK, Faraday Discuss., 130, 311-326, 2005.

Virkkula, A., Van Dingenen, R., Raes, F., and Hjorth, J.: Hygroscopic properties of aerosol formed by oxidation of limonene, $\alpha$ pinene and $\beta$-pinene, J. Geophys. Res., 104, 3569-3579, 1999. 